\title{
1 Epidemiology of Strongyloides stercoralis on Mekong Islands in Southern Laos
}

2 Youthanavanh Vonghachack ${ }^{\mathrm{a}, \mathrm{b}, \mathrm{c}}$, Somphou Sayasone, ${ }^{, \mathrm{d}}$, Dalouny Bouakhasith ${ }^{\mathrm{a}}$, Keoka

3 Taisayavong ${ }^{\mathrm{e}}$, Kongsap Akkavong $^{\mathrm{d}}$, Peter Odermatt $^{\mathrm{b}, \mathrm{c}}$ *

4

5

${ }^{\text {a }}$ Faculty of Medical Sciences, University of Health Sciences, Vientiane Capital, Lao People

6 Democratic Republic

7 b Department of Epidemiology and Public Health, Swiss Tropical and Public Health

8 Institute,P.O. Box, CH-4002 Basel, Switzerland

9 c University of Basel, P.O. Box, CH-4003 Basel, Switzerland

d National Institute of Public Health, Ministry of Health, Vientiane Capital, Lao People

11 Democratic Republic

e Malaria station in Champasack Province, Ministry of Health, Vientiane Capital, Lao People Democratic Republic

Key words: Strongyloides stercoralis, Epidemiology, Baermann technique, Mekong Island, Laos

18 * Correspondence: Peter Odermatt, Department of Public Health and Epidemiology, Swiss

19 Tropical and Public Health Institute, P.O. Box, CH-4002 Basel, Switzerland; Tel.: +41-61284 8214; Fax: +41-61-284 8105; E-mail: peter.odermatt@unibas.ch 
Strongyloides stercoralis is a neglected helminth infection potentially leading to a systemic infection in immunocompromised individuals. In Lao People's Democratic Republic (Lao PDR, Laos), information on S. stercoralis infection is scarce. We assessed S. stercoralis infection and associated risk factors and symptoms on the Mekong Islands in southern Laos. On two stool samples Baermann and Kato-Katz techniques were performed to detect S. stercoralis larvae and concomitant helminth infections. Among 729 individuals, $41.0 \%$ were infected with S. stercoralis. Men were at higher risk than women (OR 1.92). Urticaria and body itching was associated with S. stercoralis infection (OR 2.4). Infection with Opisthorchis viverrini (72.2\%), Schistosoma mekongi (12.8\%), and hookworm (56.1\%) were very common. Few infections with Trichuris trichiura (3.2\%), Ascaris lumbricoides $(0.3 \%)$ and Taenia spp. $(0.3 \%)$ were detected. The majority of helminth infections were of light intensity in prevalences of $58.0 \%, 52.1 \%, 8.2 \%, 3.3 \%$ and $0.3 \%$, for $O$. viverrini, hookworm, S. mekongi, T. trichiura and A. lumbricoides respectively. Nevertheless, heavy infection intensities were observed for O. viverrini (0.7\%), S. mekongi $(1.8 \%)$ and hookworm (1.7\%). S. stercoralis is highly endemic on islands of Khong district, Champasack province, southern Laos. The national helminth control programme should no longer neglect the presence of this helminth infection. 


\section{Introduction}

Strongyloides stercoralis is one of the most neglected soil-transmitted helminthiases (STH) (Olsen et al., 2009). It is transmitted with unprotected contact with soil and endemic in tropical and temperate regions (Schär et al., 2013). Today, an estimated 30-100 million people are infected worldwide (Bethony et al., 2006).

The life cycle of $S$. stercoralis is complex. Humans acquire the infection by direct skin contact with infective third stage larvae (L3). Chronic infection occurs by repeated endogenous auto-infection that may last for several decades (Becker et al., 2013). Of particular clinical importance is the infection among immunocompromised patients in whom it may lead to hyperinfection syndrome and may be fatal if not treated adequately (Becker et al., 2013; Siddiqui and Berk, 2001).

In Lao Peoples' Democratic Republic (Lao PDR, Laos) information on S. stercoralis infection is scarce. The diagnostic techniques used in the country, i.e., direct smears and Kato-Katz technique (Katz et al., 1972) have a very low sensitivity (Requena-Mendez et al., 2013). Therefore, S. stercoralis infection might be missed and underestimated diagnosis in the laboratories of Hospitals in the country. However, in 1996 the prevalence of S. stercoralis in Laos was estimated at $19 \%$ in Thakek and Hinboun district, Khammouane Province, central of the country by using agars plate culture method (Vannachone et al., 1998). In many parts of the country, e.g. on the Mekong islands in Champasack province, or Saravane province, water supply and sanitation facilities are absent in communities (Sayasone et al., 2007). In addition rural populations' life style and farming activities favor transmission (e.g. intense skin contact with soil). Other helminthiasis such as STH, food-borne trematodiasis 
62 (FBT) and schistosomiasis mekongi are highly prevalent (Forrer et al., 2012; Rim et al.,

63 2003; Sayasone et al., 2007; Sayasone et al., 2011).

64 We aimed to assess S. stercoralis infection and risks on population on Mekong islands of 65 Khong district, where other helminthiases have been reported previously. We conducted a 66 cross-sectional study on three islands in Khong district, Champasack province, in Southern 67 Laos.

68 


\subsection{Ethics statement}

71

72

73

74

The study was approved by the Lao National Ethics Committee for Health Research (NECHR), Ministry of Health, Laos. All procedures were explained to provincial, district and village authorities and their approval was obtained. Study participants were informed on study procedures, benefits and risks of the study as well as their rights to withdraw at any time. Before enrolment written informed consent was obtained from all study participants and parents or legal guardians of children below the age of 15 years. In addition a written assent was obtained from children and adolescent $(<18$ years). Participants were informed about the examinations. All infections diagnosed were treated according the Lao national treatment guidelines (MOH, 2004). Those Strongyloides stercoralis infected were treated with a single $200 \mu \mathrm{g} / \mathrm{kg}$ dose of ivermectin tablet free of charge (Satoh and Kokaze, 2004; Suputtamongkol et al., 2011).

\subsection{Study area and population}

The study was conducted in March 2011 on three islands, i.e. Donlong, Donthan and Donlieng Island located in the Mekong River in Khong district, Champasack province, southern Laos. Donlong Island composes of four villages, namely Haulong, Longsong, Longkang and Hanglong village whereas Donthan and Donlieng islands compose of one village each namely Donthan and Donlieng village, respectively. Donlong, Donthan and Donlieng have a population of approximately 2,174 (Haulong: 567; Longsong: 543; Longkang: 510 and Hanglong: 554), 586 and 137 inhabitants, respectively. The main occupation of villagers in these three islands is rice subsistence farming, vegetable plantation, 
and fishing activities in the Mekong. Additionally, in Donlong a considerable number of farmers cultivate tobacco.

The study islands were selected as they represent typical islands of the Khong districts. In the study villages the Provincial Health Office reported very low per cent of households with latrines. Twenty to thirty households were chosen from the households list of the head of the village by using simple random sampling procedure. All household members aged 2 years or older were invited to participate in the study.

\subsection{Field procedures and laboratory examinations}

A household and an individual questionnaire were administered. With the household questionnaire addressed to the head of household. The following information was collected: having and using latrine at home, wearing shoes (slippers), and socioeconomic conditions by antihelminthic drugs during the past two weeks was obtained.

Two stool samples were collected per study participants within a five day period. Each sample was examined by using Kato-Katz thick smears technique (Katz et al., 1972) and Baermann technique (Garcia and Burckner, 2001). Pre-labeled plastic 30ml stool containers (ID numbers, name, age and date of stool collection) were handed out to each participant. They were asked to provide a full container of stool. Each morning, filled containers were collected and replaced with empty ones for stool collection on the following day. The stool samples were stored at ambient temperature and transferred to the laboratory of the Khong District Hospital within 2-3 hours post-collection where they were further processed. 
114 Kato-Katz and Baermann tests are described in detail elsewhere (Khieu et al., 2013a;

115 Sayasone et al., 2011). In brief, approximately $5 \mathrm{~g}$ of each stool sample was divided from

116 each stool sample for performing Baermann test (Garcia and Burckner, 2001). The stool

117 sample was placed on a gauze-lined mesh in a glass funnel equipped with a rubber tube and a

118 clamp, and covered with de-chlorinated tap-water. After 2 hours, the water (approx. $50 \mathrm{ml}$ )

119 was centrifuged and the sediment examined under a microscope for S. stercoralis larvae (L1-

120 stage). A single Kato-Katz thick smear (Katz et al., 1972) was prepared for each stool sample

121 and examined within 1 hour of preparation. Helminth eggs were counted and recorded

122 separately to obtain species-specific infection intensity estimates.

\subsection{Data management and analysis}

124 Questionnaire and stool data were double entered in EpiData version 3.1 (EpiData

125

126

127

Association; Odense, Denmark) and validated. Statistical analyses were performed in STATA version 10 (StataCorp.; College Station, USA). Only participants with complete questionnaire and stool examination were analyzed. The intensity of helminth egg counts was expressed as eggs per gram of stool (EPG) obtained from Kato-Katz examination. Intensity of helminthic infections was classified as light, moderate and heavy infection (Sayasone et al., 2009; Upatham et al., 1984; WHO, 2002). An univariate logistic regression analysis was carried out to associate potential risk factors with $S$. stercoralis infection status for which matched OR and its $95 \%$ confidence interval (CI) and $\mathrm{P}$-value were calculated. The variables with $\mathrm{P}<0.2$ in the univariate analysis were included in the multivariate logistic regression analysis. Socioeconomic status (SES) conditions in the household were calculated according to an asset-based method such as electric devices, engines, agricultural land and livestock owner, indicator data were defined by principal component analysis (PCA). SES conditions in the household were categorized into five wealth quintiles as (i) most poor, (ii) very poor, (iii) 
138 poor, (iv) less poor and (v) least poor according to their cumulative standardized asset scores.

139 Details of this widely used approach have been presented elsewhere (Sayasone et al., 2011).

140 A "smoothed" age prevalence curve was used to present the infection prevalence by mean

141 age and sex each participants.

142 


\subsection{Study population}

In total, 729 individuals had complete data records (Figure 1). They originated from 247 households on the three islands: 347 (47.6\%) and 382 (52.4\%) individuals from Donlong and Donthan/Donlieng islands, respectively; $45.7 \%$ (333) were male; all were ethnic Laoloum. Age ranged from 2 to 95 years with a median age of 30.6 years. Among the participants, illiterate, and primary and secondary school graduate were $7.0 \%, 60.8 \%$ and $29.6 \%$, respectively (Table 1 ). Only $2.6 \%$ had a technical/university level training. They lived in Donthan and Donlieng villages. The main occupation of the villagers was farming $(61.9 \%)$ such as rice, tobacco, and vegetable farming while only few were government employees $(2.5 \%)$. The socio-economic status on Donlong was significantly higher than on the other two islands $(\mathrm{p}=0.032)$.

\subsection{Strongyloides stercoralis infection and co-infections}

The overall S. stercoralis infection prevalence was $41.0 \%$ (Table 2). The infection rate did not differ between the islands (Donlong 44.1\% vs. Donthan/Donlieng 38.2\%, $\mathrm{p}=0.107$ ). Highest infection rate was observed with $O$. viverrini $(72.2 \%)$, followed by hookworm (56.1\%) and S. mekongi (12.8\%). T. trichiura (3.3\%), A. lumbricoides (0.3\%) and Taenia spp. $(0.3 \%)$. Infection prevalence of $O$. viverrini $(76.1 \%$ vs. $68.6 \%, \mathrm{p}=0.024)$ and S. mekongi $(25.6 \%$ vs. $1.0 \%, \mathrm{p}<0.001)$ was significantly higher on Donlong than on the other two islands. Whereas, hookworm infection prevalence was significantly higher on Donthan/Donlieng islands (63.9\% vs. $47.6 \%, \mathrm{p}<0.001)$.

Among the 729 individuals, only $11.1 \%$ were free of helminth infections. In $65.3 \%$ of the study participants two or more helminth infections were diagnosed. Multiple helminth 
infections were significantly more frequent on Donthan and Donlieng than on Donlong $(\mathrm{p}=0.001$, Table 2$)$.

The infection intensity of the diagnosed intestinal parasitic infections is given in Table 3 . Most diagnosed helminth infections were of light intensity, e.g. $58.0 \%$ of $O$. viverrini infections. However, heavy infection intensities were found in patients with $S$. mekongi (1.8\%), hookworm $(1.7 \%)$ and $O$. viverrini $(0.7 \%)$ infections.

\subsection{Risk factors associated with Strongyloides stercoralis infection}

The results of the risk analyses for a $S$. stercoralis infection are presented in Table 4 . The most important risk factor was gender. Male compared to female study participants had a significantly higher risk for a S. stercoralis infection by taking into account the age of the study participants (adjusted OR 1.79, 95\% CI 1.45-2.67).

S. stercoralis infection was diagnosed in participants of all ages. Children of the age group $\leq$ 5 years had the lowest infection prevalence $(33.3 \%)$. However, in none of the older age groups the infection risk increased significantly. Interestingly, the age infection prevalence was distinctly different between male and female study participants (Fig. 2). In male participants the infection prevalence reached a peak $60 \%$ in the age between 20 and 30 years, and remained at around 50\% in the older age groups. In female participants the infection reached a plateau of $38 \%$ in individuals of 10 years and remained up to 40 years, and dropped thereafter.

In our analyses none of the socio-economic risk factors such as socio-economic status, occupation and level of education was associated with S. stercoralis infection. Furthermore, also hygiene behaviours wearing shoes (slippers), having and using a latrine and having been 
treated with antihelminthic drugs in the past six months were significantly associated with $S$. stercoralis infection.

190 In the interview participants were asked to report symptoms of the last two weeks. Urticaria 191 and/or body itching during the previous two weeks was the only reported symptom

192 significantly associated with S. stercoralis infection. Having an urticarial and / or an 193 experience of itching in body parts was strongly associated with an S. stercoralis infection 194 (adjusted OR 2.40, 95\% CI=1.42-4.05, $P=0.001$ ).

195 


\section{Discussion}

197

198

199

200

201

202

203

204

205

206

207

S. stercoralis is one of the most neglected tropical diseases (Olsen et al., 2009). In resource poor countries of tropical climate favourable conditions for the transmission of the parasite prevail. Hence, S. stercoralis is most probably underreported in these settings (Schär et al., 2013). In Southeast Asia, a relative small number of studies document S. stercoralis infection. However, in recent work in Cambodia, very high infection rates of $25 \%$ in Kandal and Takeo provinces (Khieu et al., 2013a; Khieu et al., 2014b) and almost 50\% in the most northern Preah Vihear province (Khieu et al., 2014a) were reported. Furthermore, low socioeconomic status and low hygienic living conditions of the rural population were strongly associated with S. stercoralis infections.

Given the similar socio-economic and environmental living conditions of the rural population in Laos, we aimed to document the level of S. stercoralis infection rates and risk factors in Southern Laos. We used a rigorous diagnostic approach, i.e. we conducted a Baermann test on two stool samples of each participant. We found a very high S. stercoralis infection prevalence of $41.0 \%$. Among the examined risk factors only gender was significantly associated with S. stercoralis. Furthermore, reported urticaria (itching of parts of the body) was significantly associated with the infection.

In Laos only very few studies have been conducted on S. stercoralis using an adequate diagnostic approach. Most data on S. stercoralis infection stem from studies examining other soil-transmitted helminthes and / or food-borne trematodes. They reported prevalence rates below 20\% (Paboriboune et al., 2014; Sayasone et al., 2011). Given the utilisation of inadequate diagnostic techniques these reports most like underestimate the true infection 
burden in the country. Therefore, more attention should be paid to S. stercoralis in Laos by incorporating sensitive diagnostic approaches in helminth surveillance activities.

In our study, we used the Baermann method on two stool samples per enrolled patients. The infection prevalence was comparable to recent reports from Cambodia (Khieu et al., 2013a; Khieu et al., 2014a; Khieu et al., 2014b), but substantially higher than infection prevalences reported from neighbouring China (Steinmann et al., 2007; Steinmann et al., 2008) and Thailand (Jongsuksuntigul et al., 2003; Sithithaworn et al., 2003). Our diagnostic procedures could have been improved by examining more stool samples per person and by adding additional diagnostic techniques. E.g. in a study in Cambodian children three stool samples were examined per child with a combination of Baermann technique and Koga Agar plate. Taken this approach as gold standard, our examination on two samples with a Baermann technique results in a sensitivity of approximately $70 \%$ and in combination with Koga Agar plate method a 93\% sensitivity could have been reached (Khieu et al., 2013a). However, the substantial additional material costs and time efforts required for conducting the Koga-Agar plate must be taken into account when planning a field investigation. In our study, these factors did not allow that this method could be added in the diagnostic study procedures.

We identified gender as the most important risk factor in our study area. Boys and men had almost twice the risk for a $S$. stercoralis infection than girls and women. This finding is in agreement with earlier reports from Cambodia (Khieu et al., 2014a; Khieu et al., 2014b) and Laos (Vannachone et al., 1998). It is most probably the gender specific daily activities of boys (recreational) and men (agricultural) which increase the exposure to contaminated soil, and hence lead to higher infection rates.

A striking finding of our study was the high infection rate in young children. One third (33.3\%) of the children below 6 years of age were infected with S. stercoralis. Given the fact 
that these children have little daily activities outside the household, the transmission of $S$. stercoralis must take place at home. A similar observation was reported in Cambodia (Khieu et al., 2014a). In addition, in Cambodian households dogs were examined on intestinal infection and found positive for Stronyloides larvae (Schär et al., 2014). We hypothesis that humans and dogs of the same household share the Strongyloides parasites and are responsible for the contaminated soil. However, further genetic studies on human and dog derived Strongyloides parasites are required in order to conclude on anthropo-zoonotic transmission. In this context it is most interesting to note, that in the same Cambodian households the dog hookworm Ancylostoma ceylanicum was found as predominant hookworm species in humans (Inpankaew et al., 2014) documenting zoonotic transmission from dogs to humans. Given that fact that hookworm and S. stercoralis have the same transmission route a similar humandog transmission pattern of latter parasite seem likely to be present.

In our study we did not find any association between a S. stercoralis infection and risk factors related to the socio-economic status, access to sanitation facilities and hygiene behaviour of the population. These results were most surprising as earlier studies identified clear association of the parasite with low economic status and absence of sanitation facilities. E.g. Cambodian school children had an almost five fold risk increase for a S. stercoralis infection when no latrine was present at home (Khieu et al., 2013a). In addition, attributable risk analysis showed that $70 \%$ of the S. stercoralis infected could be averted if adequate sanitation would be present (Khieu et al., 2013a).

Most recent developments in our study area might have led to the absence of these associations. In fact, we selected the villages because the Provincial Health Office reported low numbers of households with latrine on villages on island in the Khong district. However, during our investigations we found that more than $40 \%$ of the households had a latrine. 
Indeed in the last year, a number of health related intervention were undertaken in the Khong district, including general health promotion activities, and latrine construction and massdeworming campaigns. We explain the absence of the associations with these new developments where people had access to improvements however remained infected with $S$. stercoralis.

271 Although S. stercoralis infection is highly prevalent in many settings its clinical significance is not understood. Long-lasting infection may contribute to chronic gastro-intestinal and skin morbidity. In our study, S. stercoralis infection was associated with reports of urticarial and/or itching body parts in the previous weeks. Very similar result reported a Cambodian study. There, urticaria with intensive itching on all body parts was reported by patients. The symptoms resolved after ivermectin treatment (Khieu et al., 2013b). However in latter report, abdominal pain was also associated with $S$. stercoralis infection.

In our study, $O$. viverrini was the most frequent helminth infection $(72.2 \%)$, followed by hookworm (56.1\%) and S. stercoralis (41.0\%) infections. In addition, a considerable $S$. mekongi infection prevalence was detected on Donlong island (25.6\%). Therefore, multiparasitism was very common. However, the clinical consequences of concurrent helminth infections are unknown. Recently, it could be shown that the co-infection with $S$. mekongi aggravates $O$. viverrini related morbidity (Sayasone et al., 2012). However, information on the contribution of $S$. stercoralis to the overall morbidity of individuals infected with multiple helminth species is unknown and will require further indepth studies. Champasack province, southern Lao PDR. The results from this study and other S. stercoralis reports from the country should not be longer neglected by the national helminth control programme. County-wide assessments on S. stercoralis infection prevalence and related 

morbidity would be most useful to further push the agenda of an intensified integrated soiltransmitted helminth control in which S. stercoralis is adequately addressed.

292

\section{Acknowledgements}

294 We are grateful to all study participants in Donlong, Donthan and Donlieng villages and the 295 local authorities for the kind collaboration. We thank all laboratory technicians.

296 


\section{References}

Becker, S.L., Vogt, J., Knopp, S., Panning, M., Warhurst, D.C., Polman, K., Marti, H., von, M.L., Yansouni, C.P., Jacobs, J., Bottieau, E., Sacko, M., Rijal, S., Meyanti, F., Miles, M.A., Boelaert, M., Lutumba, P., van, L.L., N'Goran, E.K., Chappuis, F., Utzinger, J., 2013. Persistent digestive disorders in the tropics: causative infectious pathogens and reference diagnostic tests. BMC.Infect.Dis. 13, 37.

Bethony, J., Brooker, S., Albonico, M., Geiger, S.M., Loukas, A., Diemert, D., Hotez, P.J., 2006. Soil-transmitted helminth infections: ascariasis, trichuriasis, and hookworm. Lancet 367, 1521-1532.

Forrer, A., Sayasone, S., Vounatsou, P., Vonghachack, Y., Bouakhasith, D., Vogt, S., Glaser, R., Utzinger, J., Akkhavong, K., Odermatt, P., 2012. Spatial distribution of, and risk factors for, Opisthorchis viverrini infection in southern Lao PDR. PLoS Negl.Trop.Dis. $6, \mathrm{e} 1481$.

Garcia, L. and Burckner, D., 2001. Diagnostic medical parasitology. eds WashingtonDC: American Society for Microbiology 1-179.

Inpankaew, T., Schar, F., Dalsgaard, A., Khieu, V., Chimnoi, W., Chhoun, C., Sok, D., Marti, H., Muth, S., Odermatt, P., Traub, R.J., 2014. High prevalence of Ancylostoma ceylanicum hookworm infections in humans, Cambodia, 2012. Emerg.Infect.Dis. 20, 976-982.

Jongsuksuntigul, P., Intapan, P.M., Wongsaroj, T., Nilpan, S., Singthong, S., Veerakul, S., Maleewong, W., 2003. Prevalence of Strongyloides stercoralis infection in northeastern Thailand (agar plate culture detection). J Med.Assoc.Thai. 86, 737-741.

Katz, N., Chaves, A., Pellegrino, J., 1972. A simple device for quantitative stool thick-smear technique in schistosomiasis mansoni. Rev.Inst.Med.Trop.São Paulo 14, 397-400.

Khieu, V., Schar, F., Forrer, A., Hattendorf, J., Marti, H., Duong, S., Vounatsou, P., Muth, S., Odermatt, P., 2014a. High prevalence and spatial distribution of Strongyloides stercoralis in rural Cambodia. PLoS Negl.Trop.Dis. 8, e2854.

Khieu, V., Schar, F., Marti, H., Bless, P.J., Char, M.C., Muth, S., Odermatt, P., 2014b. Prevalence and risk factors of Strongyloides stercoralis in Takeo Province, Cambodia. Parasit.Vectors 7, 221.

Khieu, V., Schar, F., Marti, H., Sayasone, S., Duong, S., Muth, S., Odermatt, P., 2013a. Diagnosis, treatment and risk factors of Strongyloides stercoralis in schoolchildren in Cambodia. PLoS Negl.Trop.Dis. 7, e2035.

Khieu, V., Srey, S., Schar, F., Muth, S., Marti, H., Odermatt, P., 2013b. Strongyloides stercoralis is a cause of abdominal pain, diarrhea and urticaria in rural Cambodia. BMC.Res.Notes 6, 200.

$\mathrm{MOH}, 2004$. Diagnosis and treatment at the district. A diagnosis and treatment guideline for the district hospital in Lao PDR. Vientiane: Ministry of Health. 
Olsen, A., van, L.L., Marti, H., Polderman, T., Polman, K., Steinmann, P., Stothard, R., Thybo, S., Verweij, J.J., Magnussen, P., 2009. Strongyloidiasis--the most neglected of the neglected tropical diseases? Trans.R.Soc.Trop.Med.Hyg. 103, 967-972.

Paboriboune, P., Phoumindr, N., Borel, E., Sourinphoumy, K., Phaxayaseng, S., Luangkhot, E., Sengphilom, B., Vansilalom, Y., Odermatt, P., Delaporte, E., Etard, J.F., Rabodonirina, M., 2014. Intestinal parasitic infections in HIV-infected patients, Lao People's Democratic Republic. PLoS One. 9, e91452.

Requena-Mendez, A., Chiodini, P., Bisoffi, Z., Buonfrate, D., Gotuzzo, E., Munoz, J., 2013. The laboratory diagnosis and follow up of strongyloidiasis: a systematic review. PLoS Negl.Trop.Dis. 7, e2002.

Rim, H.J., Chai, J.Y., Min, D.Y., Cho, S.Y., Eom, K.S., Hong, S.J., Sohn, W.M., Yong, T.S., Deodato, G., Standgaard, H., Phommasack, B., Yun, C.H., Hoang, E.H., 2003. Prevalence of intestinal parasite infections on a national scale among primary schoolchildren in Laos. Parasitol.Res. 91, 267-272.

Satoh, M. and Kokaze, A., 2004. Treatment strategies in controlling strongyloidiasis. Expert.Opin.Pharmacother. 5, 2293-2301.

Sayasone, S., Mak, T.K., Vanmany, M., Rasphone, O., Vounatsou, P., Utzinger, J., Akkhavong, K., Odermatt, P., 2011. Helminth and intestinal protozoa infections, multiparasitism and risk factors in Champasack province, Lao People's Democratic Republic. PLoS.Negl.Trop.Dis. 5, e1037.

Sayasone, S., Odermatt, P., Phoumindr, N., Vongsaravane, X., Sensombath, V., Phetsouvanh, R., Choulamany, X., Strobel, M., 2007. Epidemiology of Opisthorchis viverrini in a rural district of southern Lao PDR. Trans.R.Soc.Trop.Med.Hyg. 101, 40-47.

Sayasone, S., Rasphone, O., Vanmany, M., Vounatsou, P., Utzinger, J., Tanner, M., Akkhavong, K., Hatz, C., Odermatt, P., 2012. Severe Morbidity Due to Opisthorchis viverrini and Schistosoma mekongi Infection in Lao People's Democratic Republic. Clin.Infect.Dis. 55, e54-e57.

Sayasone, S., Vonghajack, Y., Vanmany, M., Rasphone, O., Tesana, S., Utzinger, J., Akkhavong, K., Odermatt, P., 2009. Diversity of human intestinal helminthiasis in Lao PDR. Trans.R.Soc.Trop.Med.Hyg. 103, 247-254.

Schär, F., Inpankaew, T., Traub, R.J., Khieu, V., Dalsgaard, A., Chimnoi, W., Chhoun, C., Sok, D., Marti, H., Muth, S., Odermatt, P., 2014. The prevalence and diversity of intestinal parasitic infections in humans and domestic animals in a rural Cambodian village. Parasitol.Int. 63, 597-603.

Schär, F., Trostdorf, U., Giardina, F., Khieu, V., Muth, S., Marti, H., Vounatsou, P., Odermatt, P., 2013. Strongyloides stercoralis: Global Distribution and Risk Factors. PLoS.Negl.Trop.Dis. 7, e2288.

Siddiqui, A.A. and Berk, S.L., 2001. Diagnosis of Strongyloides stercoralis infection. Clin.Infect.Dis. 33, 1040-1047. 
Sithithaworn, P., Srisawangwong, T., Tesana, S., Daenseekaew, W., Sithithaworn, J., Fujimaki, Y., Ando, K., 2003. Epidemiology of Strongyloides stercoralis in north-east Thailand: application of the agar plate culture technique compared with the enzymelinked immunosorbent assay. Trans.R.Soc.Trop.Med.Hyg. 97, 398-402.

Steinmann, P., Du, Z.W., Wang, L.B., Wang, X.Z., Jiang, J.Y., Li, L.H., Marti, H., Zhou, X.N., Utzinger, J., 2008. Extensive multiparasitism in a village of Yunnan province, People's Republic of China, revealed by a suite of diagnostic methods. Am.J.Trop.Med.Hyg. 78, 760-769.

Steinmann, P., Zhou, X.N., Du, Z.W., Jiang, J.Y., Wang, L.B., Wang, X.Z., Li, L.H., Marti, H., Utzinger, J., 2007. Occurrence of Strongyloides stercoralis in Yunnan Province, China, and Comparison of Diagnostic Methods. PLoS.Negl.Trop.Dis. 1, e75.

Suputtamongkol, Y., Premasathian, N., Bhumimuang, K., Waywa, D., Nilganuwong, S., Karuphong, E., Anekthananon, T., Wanachiwanawin, D., Silpasakorn, S., 2011. Efficacy and safety of single and double doses of ivermectin versus 7-day high dose albendazole for chronic strongyloidiasis. PLoS Negl.Trop.Dis. 5, e1044.

Upatham, E.S., Viyanant, V., Kurathong, S., Rojborwonwitaya, J., Brockelman, W.Y., Ardsungnoen, S., Lee, P., Vajrasthira, S., 1984. Relationship between prevalence and intensity of Opisthorchis viverrini infection, and clinical symptoms and signs in a rural community in north-east Thailand. Bull.World Health Organ. 62, 451-461.

Vannachone, B., Kobayashi, J., Nambanya, S., Manivong, K., Inthakone, S., Sato, Y., 1998. An epidemiological survey on intestinal parasite infection in Khammouane Province, Lao PDR, with special reference to Strongyloides infection. Southeast Asian J.Trop.Med.Public Health 29, 717-722.

WHO, 2002. Prevention and control of schistosomiasis and soil-transmitted helminthiasis. World Health Organisation Technical Report Series 912. 
401 Figure Legend

402 Figure 1: Study diagram

403 Figure 2: Age prevalence distribution by sex of Strongyloides stercoralis infection in 404 villagers from Southern Laos

405 
406 Table 1: Demographic characteristics of the study participants

\begin{tabular}{|c|c|c|c|c|c|}
\hline \multirow{2}{*}{ Characteristic } & \multirow{2}{*}{$\begin{array}{l}\text { Overall } \\
\text { n }(\%)\end{array}$} & \multicolumn{2}{|c|}{ Locality } & \multirow{2}{*}{$\mathbf{x}^{2}$} & \multirow{2}{*}{$p$-value } \\
\hline & & $\begin{array}{l}\text { Donlong } \\
\text { n }(\%)\end{array}$ & $\begin{array}{l}\text { Donthan/Donlieng } \\
\text { n (\%) }\end{array}$ & & \\
\hline $\mathbf{N}$ & 729 & $347(47.6)$ & $382(52.4)$ & & \\
\hline \multicolumn{6}{|l|}{ Age (years) } \\
\hline Mean (range) & $30.6(2-95)$ & $28.1(2-81)$ & $32.8(2-95)$ & & \\
\hline \multicolumn{6}{|l|}{ Sex } \\
\hline Female & $396(54.3)$ & $187(53.9)$ & $209(54.7)$ & & \\
\hline Male & $333(45.7)$ & $160(46.1)$ & $173(45.3)$ & 0.049 & 0.824 \\
\hline \multicolumn{6}{|l|}{ Educational level } \\
\hline Illiterate & $51(7.0)$ & $27(7.8)$ & $24(6.3)$ & & \\
\hline Primary school & $443(60.8)$ & $231(66.6)$ & $212(55.5)$ & & \\
\hline High school & $216(29.6)$ & $89(25.7)$ & $127(33.3)$ & & \\
\hline Technical school/University & $19(2.6)$ & 0 & $19(5.0)$ & 25.053 & $<0.001$ \\
\hline \multicolumn{6}{|l|}{ Occupation } \\
\hline Farmer & $451(61.9)$ & $216(62.3)$ & $235(61.5)$ & & \\
\hline Student & $212(29.1)$ & $101(29.1)$ & $111(29.1)$ & & \\
\hline Child & $48(6.6)$ & $29(8.4)$ & $19(5.0)$ & & \\
\hline Government employee & $18(2.5)$ & $1(0.3)$ & $17(4.5)$ & 15.934 & 0.001 \\
\hline \multicolumn{6}{|l|}{ Socio-economic status } \\
\hline Most poor & $146(20.0)$ & $55(15.9)$ & $91(23.8)$ & & \\
\hline Very poor & $147(20.1)$ & $69(19.9)$ & $78(20.4)$ & & \\
\hline Poor & $145(19.8)$ & $82(23.6)$ & $63(16.5)$ & & \\
\hline Less poor & $149(20.4)$ & $73(21.0)$ & $76(19.9)$ & & \\
\hline Least poor & $142(19.4)$ & $68(19.6)$ & $74(19.4)$ & 10.575 & 0.032 \\
\hline
\end{tabular}


Table 2: Prevalence of helminth infections among villagers in the islands of Khong district, Champasack province $(n=729)$

\begin{tabular}{|c|c|c|c|c|c|}
\hline Infections & $\begin{array}{c}\text { Overall } \\
\mathrm{n}=729 \\
(\%) \\
\end{array}$ & $\begin{array}{c}\text { Donlong } \\
\text { n=347 } \\
(\%) \\
\end{array}$ & $\begin{array}{c}\text { Donthan/Donlieng } \\
\mathbf{n}=382 \\
(\%)\end{array}$ & $\mathbf{x}^{2}$ & $p$-value \\
\hline \multicolumn{6}{|l|}{ Nematodes } \\
\hline Strongyloides stercoralis & $299(41.0)$ & $153(44.1)$ & $146(38.2)$ & 2.59 & 0.107 \\
\hline Ascaris lumbricoides & $2(0.3)$ & 0 & $2(0.5)$ & 1.82 & 0.177 \\
\hline Trichuris trichiura & $24(3.3)$ & $12(3.5)$ & $12(3.1)$ & 0.05 & 0.811 \\
\hline Hookworm & $409(56.1)$ & 165 (47.6) & $244(63.9)$ & 19.67 & $<0.001$ \\
\hline \multicolumn{6}{|l|}{ Trematodes } \\
\hline Opisthorchis viverrini & $526(72.2)$ & $264(76.1)$ & $262(68.6)$ & 5.08 & 0.024 \\
\hline Schistosoma mekongi & $93(12.8)$ & $89(25.6)$ & $4(1.0)$ & 98.87 & $<0.001$ \\
\hline \multicolumn{6}{|l|}{ Cestodes } \\
\hline Taenia spp. & $2(0.3)$ & $1(0.3)$ & $1(0.3)$ & 0.004 & 0.946 \\
\hline \multicolumn{6}{|l|}{ Multiparasitism } \\
\hline Non infection. & $81(11.1)$ & $50(13.1)$ & $31(8.9)$ & & \\
\hline Single infection & $172(23.6)$ & $88(23.0)$ & $84(24.2)$ & & \\
\hline Double infection & $276(37.9)$ & $155(40.6)$ & $121(34.9)$ & & \\
\hline Triple infection & $169(23.2)$ & $83(21.7)$ & $86(24.8)$ & & \\
\hline Quartile infection. & $31(4.3)$ & $6(1.6)$ & $25(7.2)$ & 18.8 & 0.001 \\
\hline
\end{tabular}

410

411 
412 Table 3: Intensity of helminth infections among villagers in the islands of Khong district, Champasack province $(\mathrm{n}=729)$

\begin{tabular}{llll}
\hline Parasites & $\begin{array}{l}\text { Light } \\
\mathrm{n}(\%)\end{array}$ & $\begin{array}{l}\text { Moderate } \\
\mathrm{n}(\%)\end{array}$ & $\begin{array}{l}\text { Heavy } \\
\mathrm{n}(\%)\end{array}$ \\
\hline $\begin{array}{l}\text { Trematodes } \\
\text { Opisthorchis viverrini }\end{array}$ & $423(58.0)$ & $98(13.4)$ & $5(0.7)$ \\
Schistosoma mekongi & $60(8.2)$ & $20(2.7)$ & $13(1.8)$ \\
$\begin{array}{l}\text { Nematodes } \\
\text { Ascaris lumbricoides }\end{array}$ & $2(0.3)$ & 0 & 0 \\
$\begin{array}{l}\text { Trichuris trichiura } \\
\text { Hookworm }\end{array}$ & $24(3.3)$ & 0 & 0 \\
\hline
\end{tabular}

414 
Table 4: Association among Strongyloides stercoralis infection and risk factors in the

\begin{tabular}{|c|c|c|c|c|c|}
\hline Characteristics & Positive, n (\%) & $\begin{array}{l}\text { Crude OR } \\
(95 \% \text { CI })\end{array}$ & $p$-value & $\begin{array}{l}\text { Adjusted OR } \\
(95 \%, \mathrm{CI}) \\
\end{array}$ & $p$-value \\
\hline \multicolumn{6}{|l|}{ Age group (years) } \\
\hline$\leq 5$ & $17(33.3)$ & 1.00 & & & \\
\hline $6-15$ & $82(40.8)$ & $1.37(0.72-2.63)$ & & & \\
\hline $16-25$ & $44(43.6)$ & $1.54(0.76-3.11)$ & & & \\
\hline $26-35$ & $44(45.4)$ & $1.66(0.81-3.36)$ & & & \\
\hline $36-45$ & $39(43.3)$ & $1.52(0.74-3.12)$ & & & \\
\hline$\geq 46$ & $73(38.6)$ & $1.25(0.65-2.41)$ & 0.708 & na & na \\
\hline \multicolumn{6}{|l|}{$\begin{array}{l}\text { Sex } \\
\end{array}$} \\
\hline Female & $134(33.8)$ & 1.00 & & 1.00 & \\
\hline Male & $165(49.6)$ & $1.92(1.42-2.58)$ & $<0.001$ & $1.97(1.45-2.67)$ & $<0.001$ \\
\hline \multicolumn{6}{|l|}{ Occupation } \\
\hline Farmer & $189(41.9)$ & 1.00 & & & \\
\hline Student & $86(40.6)$ & $0.94(0.67-1.31)$ & & & \\
\hline Government employee & $8(44.4)$ & $1.10(0.42-2.86)$ & & & \\
\hline Child & $16(33.3)$ & $0.69(0.36-1.29)$ & 0.693 & na & na \\
\hline \multicolumn{6}{|l|}{ Educational level } \\
\hline Illiterate & $17(33.3)$ & 1.00 & & & \\
\hline Primary school & $177(40.0)$ & $1.33(0.72-2.46)$ & & & \\
\hline High school & $97(44.9)$ & $1.63(0.86-3.09)$ & & & \\
\hline Technical school, University & $8(42.1)$ & $1.45(0.49-4.29)$ & 0.418 & na & na \\
\hline \multicolumn{6}{|l|}{ Having latrine at home } \\
\hline No & $194(42.2)$ & 1.00 & & & \\
\hline Yes & $105(39.0)$ & $0.87(0.64-1.19)$ & 0.405 & na & na \\
\hline \multicolumn{6}{|l|}{ Habit of defecation } \\
\hline Latrine & $105(39.5)$ & 1.00 & & & \\
\hline Bush & $156(41.7)$ & $1.09(0.79-1.51)$ & & & \\
\hline Rice field & $38(42.7)$ & $1.14(0.70-1.85)$ & 0.802 & na & na \\
\hline \multicolumn{6}{|l|}{ Last defecation } \\
\hline Latrine & $107(39.2)$ & 1.00 & & & \\
\hline Bush & $153(41.8)$ & $1.11(0.8-1.53)$ & & & \\
\hline Rice field & $39(43.3)$ & $1.18(0.73-1.92)$ & 0.715 & na & na \\
\hline \multicolumn{6}{|l|}{ Wearing slippers (shoes) } \\
\hline Yes & $249(41.8)$ & 1.00 & & & \\
\hline No & $50(37.6)$ & $1.19(0.8-1.75)$ & 0.375 & na & na \\
\hline \multicolumn{6}{|l|}{ Worked in rice field last year } \\
\hline No & $91(38.2)$ & 1.00 & & & \\
\hline Yes & $208(42.4)$ & $1.18(0.8-1.62)$ & 0.288 & na & na \\
\hline \multicolumn{6}{|c|}{$\begin{array}{l}\text { Treated with antihelminth drugs in } \\
\text { past } 6 \text { months }\end{array}$} \\
\hline No & $264(42.1)$ & 1.00 & & & \\
\hline Yes & $33(34.0)$ & $0.7(0.45-1.11)$ & & & \\
\hline Don't remember & $2(40.0)$ & $0.91(0.15-5.52)$ & 0.314 & na & na \\
\hline \multicolumn{6}{|l|}{ Socio-economic status } \\
\hline Most poor & $69(47.3)$ & 1.00 & & & \\
\hline Very poor & $52(35.4)$ & $0.61(0.38-0.97)$ & & & \\
\hline Poor & $64(44.1)$ & $0.88(0.55-1.39)$ & & & \\
\hline Less poor & $56(37.6)$ & $0.67(0.42-1.06)$ & & & \\
\hline Least poor & $58(40.9)$ & $0.77(0.48-1.22)$ & 0.231 & na & na \\
\hline \multicolumn{6}{|l|}{ Study villages } \\
\hline Donthan/Donlieng & $146(38.2)$ & 1.00 & & & \\
\hline Donlong & $153(44.1)$ & $1.27(0.94-1.71)$ & 0.107 & na & na \\
\hline
\end{tabular}

417 na not applicable 
